\author{
Rational Rhymes for Addressing Common Childhood Issues \\ Jeffrey M. Warren \\ University of North Carolina at Pembroke
}

Author Note

Jeffrey M. Warren, Departments of Professional Pedagogy \& Research and School Administration \& Counseling, University of North Carolina at Pembroke.

Correspondence concerning this article should be addressed to Jeffrey M. Warren, UNC-Pembroke, School of Education, P.O. Box 1510, 1 University Place, Pembroke, North Carolina 28372.

Email: jeffrey.warren@uncp.edu 


\begin{abstract}
Music-based interventions are valuable tools counselors can use when working with children. Specific types of music-based interventions, such as songs or rhymes, can be especially pertinent in addressing the thoughts, feelings, and behaviors of children. Rational Emotive Behavior Therapy (REBT) provides a therapeutic framework that encourages these types of creative interventions. Rational songs or rhymes can be utilized to challenge irrational thoughts, reduce unhealthy negative feelings, and encourage helpful behaviors. The purpose of this article is to provide counselors with a rationale for utilizing rhymes as therapeutic interventions when working with children. Additionally, ten rhymes are presented based on specific REBT concepts including: (a) the connection between thoughts, feelings, and behaviors, (b) demands, (c) low frustration tolerance, (d) awfulizing, and (e) self-rating.
\end{abstract}

Keywords: creativity, counseling, rational emotive behavior therapy, music, rhymes 


\section{Rational Rhymes for Addressing Common Childhood Issues}

Creativity is widely encouraged and supported in professional counseling (Carson \& Becker, 2004; Gladding, 2005; Gladding \& Henderson, 2000). Creative counseling interventions can include the use of art, bibliotherapy, games, music, puppets, and role-plays (Bradley, Gould, \& Hendricks, 2004). These interventions may allow children to maintain a sense of control while exploring their thoughts and feelings (Frels, Leggett \& Larocca, 2009).

Counselors can utilize music to impact psychological and physiological health (Koelsch, 2009). While considered a creative intervention in counseling, music is also a common form of expression found in the daily lives of children. According to Shipps (2010), in 2009 the average child listened to over two hours of music a day. Moreover, Gladding (2005) suggested music is a multicultural experience that stretches around the world. Due to its wide spread virtue, music can be a powerful avenue available to counselors when working with children. Children may also respond well to music interventions because of their natural appreciation for song and rhythm.

Gladding (2005) considered music a "therapeutic ally to the verbal approaches of counseling” (p. 14). Music can be an engaging component of counseling process. Music and song has been incorporated in Rational Emotive Behavior Therapy (REBT; Ellis, 1962) since its inception in the mid 1950s. Ellis (1977) wrote numerous songs applicable in counseling the adult client. More recently, Vernon $(1993,2004,2010)$ and Warren $(2009,2010)$ have emphasized the importance of music and songs as interventions for teaching children principles of REBT.

The purpose of this article is to provide counselors with a rationale for utilizing music interventions, specifically rhymes, when counseling children. A variety of rhymes based on the 
principles of REBT are provided. These rhymes specifically address common childhood issues. Music, including rhymes, can have a positive influence on mental health of children (Gladding, 2005). However, there are few resources available that supply counselors with theoreticallybased rhymes for therapeutic use.

\section{The Use of Music in Counseling Children}

Degmecic, Pozgain, and Filakovic (2005) suggested music serves many functions in the therapeutic process including exploring personal feelings, making positive changes, increasing sense of control, and enhancing self-awareness. Music can also be utilized to support healthy feelings, thoughts, and behaviors. These functions of music are all applicable to the issues for which children seek or are referred for mental health services.

Music therapy, a helping profession similar to professional counseling, utilizes music interventions to promote wellness and mental health of children as well. The American Music Therapy Association (AMTA; 2009) identified music therapists as "credentialed professionals who have completed an approved music therapy program" (Preamble, para. 1). Due to the specialized training music therapists receive, their work may be different from that of professional counselors using music as expressive techniques. Music-based interventions provided by counselors are typically allusive and less comprehensive (Gladding, 2005).

Counselors utilize music in many ways when working with children. For example, counselors can facilitate the counseling process by assisting children in song writing, learning and singing songs, and listening to music (Vernon, 2004). Warren and Weaver (2007) suggested school counselors can utilize song and music during classroom guidance lessons as a way to teach students about respect, responsibility, and self-control. Songs can also be used to develop behavioral awareness and reduce impulsivity (Vernon, 2010). Crabbs, Crabbs, and Wayman (as 
cited in Gladding, 2005) suggested that children are able to learn, have fun, and bond with others through music.

There is much support for the use of music in counseling children. However, counselors should use music-based interventions that are culturally appropriate. It is important for counselors to maintain awareness of their personal biases and consider clients' worldviews when selecting interventions (Thompson \& Henderson, 2006).

\section{Rational Emotive Behavior Therapy}

Rational Emotive Behavior Therapy (Ellis, 1962) is a cognitive-behavioral therapy that focuses on helping people identify and challenge irrational beliefs in an effort to lead happier, more productive lives. An irrational belief comprises a rigid, dogmatic inference followed by an extreme evaluation of an adverse situation (Dryden \& Branch, 2008). Irrational beliefs often include "shoulds," "musts," or "oughts" and one of three derivatives, "I can't stand it," "it's awful," or "I'm worthless." An example of an irrational belief is "I should get what I want and it's awful when I don't." Ellis and Wilde (2002) suggested that these beliefs lead to intense emotions such as anger, anxiety, depression, and guilt and dysfunctional behaviors such as avoidance.

REBT encourages clients to identify and challenge irrational beliefs while developing a more rational philosophy of life. Rational beliefs are the hallmark of a rational philosophy of life. Rational beliefs are preferential and non-dogmatic in nature. An example of a rational belief is "I would like to get my way, but it is ok if I don't." These types of thoughts typically lead to healthy emotions such as sadness or annoyance and helpful behaviors. Counselors can use cognitive, emotive, or behavioral techniques when assisting client in challenging and replacing irrational beliefs with more rational, functional ones. Cognitive techniques including 
functional, logical, and empirical disputes, largely involve direct challenges of irrational beliefs. Emotive and behavioral interventions, such as imagery or shame attacking exercises, often support and solidify the client's shift towards a rational philosophy (Ellis \& MacLaren, 2005).

\section{Application of Music in REBT when Counseling Children}

Rational Emotive Behavior Therapy encourages counselors and clients to use a wide variety of interventions in ways that are aligned with its therapeutic philosophy. Music-based interventions appear to be creative, complementary additions when working from an REBT framework, especially when counseling children. For example, Vernon $(1993,2009)$ suggested children can compose their own lyrics to explain and explore issues they may be facing. Another strategy involves the counselor and client creating songs that address REBT concepts (Vernon, 2004). Vernon (2010) and Warren $(2009,2010)$ identified several songs and rhymes useful in addressing the thoughts, feelings, and behaviors of children.

In REBT, rational songs function as cognitive, emotive, and behavioral challenges or disputes (Ellis, 2002). Rational songs and rhymes encourage rational thinking, healthy negative emotions, and helpful behaviors. Cognitively, music can be utilized to directly address and challenge irrational thoughts. For example, Vernon (2010) described a song titled, "I Can Stand It" aimed at challenging irrational thoughts related to frustration tolerance. Music can also elicit emotions through rhythm and its expressive nature. Counselors may ask clients to sing loudly or emphatically to assert their new rational positions. Behaviorally, children can repeat rational rhymes in an effort to facilitate rational thinking. Allowing children to move their body or dance may further increase internalization of rational messages.

Rational songs and rhymes can be integrated throughout the counseling process. They can serve as the main intervention, a complementary addition to a session, or as homework. As a 
main intervention, the rhymes can be rote taught along with an exploration of content and discussion of application to the client's life. Counselors may choose to rote teach a rhyme that is supplemental to the focus of the session. Additionally, clients may be asked to rehearse a rhyme twice a day or to teach it to their parents as homework. Counselors should refer to clients' treatment goals and plans to determine the most appropriate uses of rational rhymes.

Incorporating rational songs and rhymes when counseling children has the potential to positively influence their mental health.

\section{Rational Rhymes}

The rational rhymes below are all original works by the author of this article. They are presented as a resource for counselors working with children. The rhymes can be spoken, sang, or rapped depending on the preferences of clients and counselors. These rhymes are based on the theory and philosophy of REBT. The lyrics encourage preferential thinking, including high frustration tolerance, anti-awfulizing, and unconditional self-acceptance. These rhymes are categorized by several REBT concepts titled, (a) connecting thinking, feeling, and behaving, (b) demanding, (c) low frustration tolerance, (d) awfulizing, and (e) self-rating. A brief description of each concept is provided along with two rhymes that can immediately be utilized when counseling children. These rhymes are applicable in individual and group counseling as well as in various settings (i.e., school, agency, private practice). These rational rhymes are most appropriate for children seven to twelve years old. They can also be used when working with children younger than seven. However, some of the terms (i.e., consequences, react, demands) may need to be modified or introduced to children. 


\section{Connecting Thinking, Feeling, and Behaving}

REBT posits that people disturb themselves based on their views of reality (Dryden, 2003; Ellis, 2001). Adults and children, often have a difficult time understanding this concept. Children often hear adults make comments such as, "it made me so angry," or "he hurt my feelings." These statements support the premise that other people or things cause one to feel in certain ways. However, REBT suggests thoughts largely determine how a person feels toward an event or situation. Furthermore, the emotions experienced during an adverse situation lead to either helpful or unhelpful behaviors. This notion is central for children in taking responsibility for their emotions and actions.

A common goal for children in counseling is the development of emotional and behavioral responsibility (Doyle \& Tergesen, 2006). Counselors can use rhymes to help children connect their thinking, feeling, and behaving. For example, these rhymes can be presented during psycho-educational sessions conducted early in the counseling relationship. Introducing these rhymes may help orient children in an REBT-based philosophy of life. Teaching children that they are responsible for their own emotions and behaviors promotes a sense of control and awareness of their life.

\section{MY THINKING IS CONNECTED TO MY...}

My thinking is connected to my feelings.

My feeling is connected to my actions.

My actions are connected to a consequence.

And that's how the story goes.

"He shouldn't have done that!," is connected to me getting mad.

Getting mad is connected to me yelling. Yelling is connected to me wasting time. And that's how the story goes! 


\section{WHEN I THINK THIS}

When I think this,

I feel like that.

When I feel like that, I react like this.

Oh...Don't you agree, the connection is plain to see.

Yes, it's true for you and me!

Oh yes...it's true for you and me.

\section{Demanding}

Demands are rigid thoughts that include words such as "must," "should," or "ought" (Ellis, 2002). Demands may be placed on others, life, or the self. Anger, depression, anxiety, and other unhelpful negative emotions, are often the result of unmet demands. These intense emotions may lead children to behave in self-defeating ways. Unfavorable consequences, applied by parents and teachers, are often the result. Preferential or flexible thoughts, however, can lead to helpful emotions such as bother or frustration and helpful behaviors (Dryden, 2003). These songs are designed to encourage flexible thinking and challenge rigid, dogmatic thoughts.

Children may place demands on life (i.e., "I must get what I want”), others (i.e., "you should do what I say"), and themselves (i.e., "I must not make a mistake"). These demands frequently lead to unhealthy negative emotions such as anger or depression (Doyle \& Terjesen, 2006). Counselors can use these rhymes when working with children that experience intense emotions. For example, children that become angry when told "no" likely think they should or must get their way. By teaching these rhymes to children, they may begin to understand that they could be happier if they thought differently (i.e., flexibly, preferentially). 


\section{TO THE E TO THE M-A-N-D}

D to the $\mathrm{E}$ to the M-A-N-D!

Demands don't work for me.

'Cause I live flexibly!

That's right, I live FLEXIBLY!

\section{WANT TO BE HAPPY!}

If I think that people should and must do what I say, Then I'll make myself mad, likely have a bad day.

But that's not the way that's best for me.

I want to be happy can't you see.

I want to be happy can't you see!

If I think that life should go just right, I'll likely get mad and complain and gripe.

But that's not the key to helping me.

I want to be happy can't you see.

I want to be happy can't you see!

\section{Low Frustration Tolerance}

Low frustration tolerance beliefs suggest an event is unbearable or intolerable (Dryden, 2003). For example, a child may think, "I should get my way and I can't stand it when I don't!" This belief may lead the child towards anger and a potential tantrum because not getting her or his way is perceived as unbearable. Children may be more successful in their interactions with adults and peers when high frustration tolerance beliefs are developed. It is important for children to learn that most negative situations they encounter in life are bearable, although not desirable. These songs challenge low frustration tolerance beliefs and encourage children to "hang in there" when life becomes tough.

Counselors can utilize these rhymes to increase tolerance in children experiencing frustration. For example, children may give up easily on classroom or homework assignments, 
fail to complete projects, or stop playing a game when they are losing. It is important children believe that they can "stand" difficult situations and do not have to immediately receive what they want (Bernard, Ellis, \& Terjesen, 2006). In these examples, rational rhymes may lead children to realize that everyday situations may be tough, but not unbearable.

\section{NOBODY ALWAYS GETS THEIR WAY}

If I think that I must, need to get my way!

It's likely that I'm gonna, have a yucky day. Thinking like that is not $\mathrm{OK}$. Cause nobody always gets their way!

\section{THINK I CAN!}

I can stand it, longer than I think I can.

If it was that bad, it'd probably be banned.

I can do it!

I'm gonna get through it.

I can stand it, because I think I can!

\section{Awfulizing}

Children sometime think the outcome of an event is horrible. For example, a child may misspell a word on a spelling test and think, "I shouldn't have missed a word, and it's terrible I did." The child is considered to be awfulizing when this occurs. Evaluating negative situations as awful suggests that the event is completely bad (Ellis \& MacLaren, 2005). The term "catastrophizing" and phrase "making a mountain out of a molehill" are synonymous with awfulizing. Counselors can help children realistically assess adverse events by challenging these irrational beliefs. The rhymes below demonstrate that negative events, such as misspelling a word on a spelling test, may not be desirable, but are far from horrible. 
Counselors can utilize these rhymes when working with children that struggle with "letting things go." For instance, some children experience anxiety related to going to school, reading aloud in class, or being teased on the playground. Children diagnosed with attention deficit-hyperactivity disorder often experience anxiety related to awfulizing (Doyle \& Terjesen, 2006). These songs support the concept that "things are not as bad as they seem." Counselors can assist children in overcoming awfulizing by encouraging realistic evaluations of life.

\section{NO BIG DEAL!}

If I want to moan and cry,

I can, I can.

'Cause when I don't get my way,

I'm not a fan.

What good comes of it, when I cry and whine?

Take a deep breath and say, I will be fine.

No big deal! No big deal!

It's alright, it's $\mathrm{OK}$, NO BIG DEAL!

\section{FIND A CHAIR}

I can find a chair, and tell it how I feel. When I'm through talking, I'll see it's no big deal.

If a chair helps me get through it, then why not do it. I can find a chair, and tell it how I feel.

\section{Self-Rating}

Messages children receive from daily experiences at school and home include, "If I am good at a task, I am good," and "If someone calls me stupid, I must be stupid." While these thoughts are not logical or realistic, children often conclude they are. As a result, children 
frequently rate their essence or self on the comments of others (Ellis \& Wilde, 2002). It is important however, for children to like, even love, themselves despite their flaws. Children should not view their worth as conditional upon their attributes or how they are viewed by others. These rhymes address issues of self-rating and encourage children to like themselves, because they are special regardless of any message they may receive.

Counselors can teach these rhymes to children that are struggling with low self-esteem or feelings of worthlessness. For example, children may mentally "beat themselves up" because they lost a game or did not get a good grade on a test. Children can be encouraged to accept themselves despite their behaviors or characteristic, whether good or bad (Bernard, Ellis, Terjesen, 2006). Counselors can use these rhymes to demonstrate and iterate the importance of children valuing themselves despite hardships or fallible traits.

\section{LIKE ME}

I like me in the morning,

I like me at night.

I like me all day long. Not just 'cause I'm funny and bright.

I'm glad I feel this way. I'm gonna sing it loud.

'Cause when it comes to me...

I AM PROUD!

\section{AM SPECIAL}

I am special and I like me!

I am special, can't you see. You can call me a dog, a rat, or a flea!

But I am special and I like me!

I am special because I am me! 


\section{Conclusion}

There are many benefits of integrating the creative arts in counseling (Gladding, 2005). Creativity can support a brief, solution-focused approach while placing the client in an active role in the counseling process (Carson \& Becker., 2004). Music-based interventions, specifically, may provide clients a medium to promote well-being and mental health (Rudd, 2008). Clients can relax, relate to, retell an event, or reeducate themselves through music. Counselors can utilize music-based interventions, in particular, to provide clients with a personal connection and point of reference when addressing irrational beliefs. Rational rhymes may be effective in helping children overcome childhood issues by encouraging flexible and preferential philosophies of life. However, more research is needed to substantiate the effectiveness of music in REBT with children. 


\section{References}

American Music Therapy Association. (2009). AMTA standards of clinical practice. Retrieved from http://www.musictherapy.org/standards.html

Bernard, M. E., Ellis, A., \& Terjesen, M. D. (2006). Rational-emotive behavioral approaches to childhood disorders: History, theory, practice and research. In A. Ellis \& M. E. Bernard (Eds.), Rational emotive behavioral approaches to childhood disorders: Theory, practice and research (pp. 3-84). New York, NY: Springer.

Bradley, L. J., Gould, L. J., \& Hendricks, P. B. (2004). Using innovative techniques for counseling children and adolescents. In A. Vernon (Ed.), Counseling children and adolescents (3rd ed., pp. 75-107). Denver, CO: Love Publishing Company.

Carson, D. K., \& Becker, K. W. (2004). When lightning strikes: Reexamining creativity in psychotherapy. Journal of Counseling and Development, 82, 111-115.

Degmecic, D., Pozgain, I., \& Filakovic, P. (2005). Music as therapy. IRASM 36, 2, 287-300.

Doyle, K. A., \& Terjesen, M. D. (2006). Rational-emotive behavior therapy and attention deficit hyperactivity disorder. In A. Ellis \& M. E. Bernard (Eds.), Rational emotive behavioral approaches to childhood disorders: Theory, practice and research (pp. 281-309). New York, NY: Springer.

Dryden, W., \& Branch, R. (2008). The fundamentals of rational emotive behavior therapy: A training handbook (2nd ed.). West Sussex, England: John Wiley \& Sons Ltd.

Dryden, W. (2003). 'The cream cake made me eat it': An introduction to the ABC theory of REBT. In W. Dryden (Ed.), Rational emotive behaviour therapy: Theoretical developments (pp. 1-21). New York: Brunner-Routledge.

Ellis, A., \& Wilde, J. (2002). Case studies in rational emotive behavior therapy with children 
and adolescents. Upper Saddle River, NJ: Pearson Education, Inc.

Ellis, A. (1962). Reason and emotion in psychotherapy. Secaucus, NJ: Citadel.

Ellis, A. (1977). A garland of rational songs. New York: Institute for Rational-Emotive Therapy.

Ellis, A. (2001). Feeling better, getting better, and staying better. Atascadero, CA: Impact Publishers.

Ellis, A. (2002). Overcoming Resistance: A rational emotive behavior therapy integrated approach (2nd ed). New York: Springer Publishing Company.

Ellis, A., \& MacLaren, C. (2005). Rational emotive behavior therapy: A therapists guide ( $2^{\text {nd }}$ ed). Atascadero, CA: Impact Publishers.

Frels, R. K., Leggett, E. S., \& Larocca, P. S. (2009). Creativity and solution-focused counseling for a child with chronic illness. Journal of Creativity in Mental Health, 4, 308-319. doi:10.1080/15401380903372646

Gladding, S. T., \& Henderson, D. A. (2000). Creativity and family counseling: The SCAMPER model as a template for promoting creative processes. The Family Journal, 8, 245-249. doi:10.1177/1066480700083005

Gladding, S. T. (2005). Counseling as an art: The creative arts in counseling (3rd ed.). Alexandria, VA: American Counseling Association.

Koelsch, S. (2009). A neuroscientific perspective on music therapy. The Neurosciences and Music III-Disorders and Plasticity, 374-384.

Rudd, E. (2008). Music in therapy: Increasing possibilities for action. Music and Arts in Action, 1, 46-60. Retrieved from: http://musicandartsinaction.net/index.php/maia/article/ view/musicintherapy

Shipps, E. (2010). Media in the lives of 8- to 18- year- olds. Radio: The Radio Technology 
Leader.

Thompson, C. L., \& Henderson, D. A. (2006). Counseling children (7th ed.). Pacific Grove, CA: Thompson Brooks/Cole.

Vernon, A. (1993). Developmental assessment and intervention with children and adolescents. Alexandria, VA: American Counseling Association.

Vernon, A. (2004). Applications of rational emotive behavior therapy with children and adolescents. In A. Vernon, (Ed.), Counseling children and adolescents (3rd ed., pp. 163187). Denver, CO: Love Publishing Company.

Vernon, A. (2009). More what works when with children and adolescents: A handbook of individual counseling techniques. Champaign, IL: Research Press.

Vernon, A. (2010, March). What works when with children and adolescents: Innovative individual counseling interventions. Presented at annual American Counseling Association Convention, Pittsburgh, PA.

Warren, J. M., \& Weaver, F. (2007, October). Strummin'for success. Presented at annual North Carolina School Counselors Association Conference, Greensboro, NC.

Warren, J. M. (2009). The Rational Instincts. Retrieved from http://jeffreywarren.net/ The_Rational_Instincts.html

Warren, J. M. (2010, February). The ins and outs of rational emotive behavior therapy. Presented at annual North Carolina Counseling Association Conference, Concord, NC. 